\title{
UMA EXPERIÊNCIA DE EAD SOB AVALIAÇÃO: A PERSPECTIVA DISCENTE SOBRE A GRADUAÇÃO EM HISTÓRIA NA UAB/UNICENTRO
}

Janaína Helfenstein | janaina helfenstein@yahoo.com.br Especialista em Formação de Professores para Docência no Ensino Superior Universidade Estadual do Centro-Oeste - UNICENTRO.

\section{Resumo}

Com o fim de produzir subsídios para a avaliação do curso de licenciatura em História na modalidade EAD da UNICENTRO/UAB, o presente artigo apresenta um perfil dos discentes que o integram, bem como investiga as motivaçóes que os levaram a optar por essa modalidade de ensino. Ao longo da pesquisa foi possível, ainda, ouvir os alunos e mensurar suas opinióes a respeito das vantagens e desvantagens da modalidade de ensino que escolheram (EAD), de seus níveis de satisfação com o curso de licenciatura em que estão inseridos (História), do material didático disponibilizado e, finalmente, da oportunidade de conquistarem uma formação profissional de nível superior. Para a realização deste estudo foi elaborado um questionário estruturado, submetido aos acadêmicos matriculados nos cinco polos UAB/UNICENTRO em que o referido curso de História é oferecido. Para a compreensão dos dados obtidos, as informações coletadas foram sistematizadas em gráficos e quadros que possibilitaram a obtenção das análises e conclusões apresentadas ao longo deste texto. A partir do estudo empreendido, foi possível constatar que a EAD é um viabilizador positivo da proliferação do ensino superior, na perspectiva dos discentes consultados. Em particular, concluímos que, sob o ponto de vista dos alunos que o integram, o curso de licenciatura em História, na modalidade EAD oferecido pelo Departamento de História do Campus Santa Cruz da UNICENTRO cumpre uma das principais propostas do Programa UAB do Governo Federal, que é permitir o acesso ao ensino superior daquelas pessoas que não teriam oportunidade de cursar uma graduação no modelo presencial.

\section{Palavras-chave}

Educação a distância; História; UAB; Avaliação. 


\section{AN EXPERIENCE OF DE UNDER \\ EVALUATION: A PERSPECTIVE ON \\ GRADUATE STUDENTS IN THE HISTORY \\ UAB/UNICENTRO}

\section{ABSTRACT}

In order to produce data for the Degree in History evaluation in the distance education modality (DE) UNICENTRO/UAB, this article presents a profile of students who integrate it, as well as investigates the motivations that led them to choose this type of education. Throughout the research, it was also possible to listen to students and measure their opinions about the advantages and disadvantages of the teaching method they chose $(\mathrm{DE})$, their levels of satisfaction with the degree course which they study (History), the available course material and the opportunity to acquire a higher education degree. For this study, a structured questionnaire was prepared and submitted to scholars from five centers UAB/UNICENTRO where their degree course is offered. To understand the acquired data, the collected information was systemized into tables and graphs that made it possible to obtain the analysis and conclusions presented in this text. From the study undertaken, it was established the DE is a positive facilitator of the higher education proliferation, from the perspective of consulted students. In particular, we conclude that $\mathrm{DE}$, from the point of view of students that are part of History Degree, in distance education mode, offered by the History Department of the Santa Cruz Campus UNICENTRO, fulfills the central proposal of the Federal Government's Program UAB which is to allow access to higher education to people who would not have opportunity to attend a graduation in the model face.

\section{Keywords:}

Distance Education, History, UAB; Evaluation.

\section{UNA EXPERIENCIA DE CONFORMIDAD CON LA EVALUACIÓN: UNA PERSPECTIVA DE LOS ESTUDIANTES DE POSTGRADO EN LA HISTORIA UAB/UNICENTRO}

\section{RESUMEN}

Con el fin de producir datos para la evaluación de la Licenciatura en Historia en la forma de educación a distancia UNICENTRO/UAB, este artículo presenta un perfil de estudiantes que integran e investiga las motivaciones que les llevaron a elegir este tipo de educación. A lo largo de la investigación fue posible escuchar a los estudiantes y medir sus opiniones sobre las ventajas y desventajas del método de enseñanza que eligieron (DE), sus niveles de satisfacción con el curso de graduación en la que viven (Historia), el material didáctico y, finalmente, la oportunidad de ganar un título de educación superior. Para este estudio un cuestionario estructurado fue presentado a los académicos inscritos en los cinco polos de la UAB/UNICENTRO donde se ofrece este curso de la historia. Para entender los datos, la información recogida se introdujo en tablas y gráficos, permitido obtener los análisis y las conclusiones se presentan en este texto. Desde el estudio realizado, se estableció que la $\mathrm{DE}$ es un elemento positivo de la proliferación de la educación superior en el punto de vista de los estudiantes referidos. En particular, se concluye que, desde el punto de vista de los estudiantes que forman parte de la Licenciatura en Historia en la modalidad de Educación a Distancia que ofrece el Departamento de Historia de la Santa Cruz Campus UNICENTRO, es una de las principales propuestas de la UAB Programa de Gobierno Federal, que es permitir el acceso a la educación superior a personas que no tienen oportunidad de asistir a una graduación en la cara del modelo.

\section{Palabras clave:}

educación a distancia; historia; UAB; evaluación 


\section{INTRODUÇÃO}

O desenvolvimento tecnológico, associado a práticas mais solidárias e consequentes de relações interpessoais, constituiu-se, nas últimas décadas, no grande apelo das sociedades que se pretendem competitivas no cenário internacional. As chamadas novas tecnologias, vedetes desse desenvolvimento, permeiam as mais variadas esferas da ação humana, com especial presença nos meios de comunicação. $\mathrm{O}$ acesso irrestrito à informação deixa de ser um assunto de Estado para tornar-se um problema de governo; prova disso é o estímulo concedido pelo Ministério da Educação e Desporto do Brasil (MEC) à formação de professores por meio de recursos tecnológicos de ensino a distância. O estabelecimento de convênios com instituições públicas locais e regionais, principalmente universidades e prefeituras, a configuração e a manutenção de grupos de profissionais mediadores $\neg$ - professores, pesquisadores e tutores -, o investimento na produção de materiais didáticos específicos para a educação não presencial e semipresencial, bem como a disponibilização de recursos destinados a subsidiar o suporte técnico necessário se configuram como estratégias colocadas em prática pelo MEC para suprir a ausência de profissionais qualificados naquelas regiões onde as modalidades convencionais de formação superior não existem ou encontram-se exclusivamente nas mãos da iniciativa privada ${ }^{1}$.

O tema não é novo. De acordo com Maria Elizabeth de Almeida (2010), a Educação a Distância (EAD) tem sido utilizada desde meados do século XIX. Primeiramente com o uso do correio e, pelo menos desde as últimas décadas do século passado, valendo-se da utilização extensiva de tecnologias tradicionais de comunicação como o rádio e a televisão associados aos materiais impressos enviados pelo correio, o que favoreceu a disseminação e a democratização do acesso à educação em diferentes níveis, permitindo atender a grande massa de alunos (ALMEIDA, 2010, p. 1).

Nesse ínterim, as tecnologias de informação $e$ comunicação trouxeram novas perspectivas para os meios educacionais, tanto presenciais como ( $e$ principalmente) a distância.

A EAD, durante muito tempo, foi vista como um recurso viabilizador possível para a conquista de uma profissão de nível técnico ou superior. Não vai longe, entretanto, o tempo em que os profissionais formados por meio de sistemas de ensino não presenciais e semipresenciais, geralmente com o uso de apostilas, eram pejorativamente chamados de profissionais formados por correspondência. José Manuel Moran, em artigo de 2007, comenta a questão do preconceito que essa modalidade de ensino vem sofrendo. Segundo o autor,

a EAD sempre esteve vinculada, no Brasil ao ensino técnico, desde a década de 40 com o Instituto Monitor e o Instituto Universal Brasileiro. Depois, ao ensino de adultos - os antigos supletivos - com os Telecursos. Por isso, ainda resiste o preconceito com a $E A D$, principalmente no ensino superior (MORAN, 2007, p. 1).

Contudo, de acordo com Jaílson de Oliveira Arieira (2009), devido ao desenvolvimento das chamadas tecnologias da informação, a EAD vem gradativamente ganhando respeitabilidade como meio de formação, pois inseriu-se no campo mais amplo do processo de inclusão digital.

Esse autor afirma que o principal papel da EAD não é substituir a educação presencial, mas sim complementá-la, multiplicando as possibili-

\footnotetext{
${ }^{1}$ Maria Luiza Belloni, no artigo intitulado Ensaio sobre Educação a Distância no Brasil (2002), discorre a respeito das diversas experiências em EAD no Brasil e sobre como esta modalidade de ensino tornou-se uma política de desenvolvimento estratégico colocada em prática tanto pelo governo federal quanto por empresas privadas.
} 
dades de acesso dos interessados à formação de nível técnico e superior. Por tal característica de rápida disseminação da formação técnica e superior, a EAD - quando colocada frente ao ensino presencial - destaca-se por conferir redobrada atenção aos critérios e ações que constantemente atestem a sua qualidade. No que concerne às estratégias pedagógicas adotadas na EAD, Arieira (2009) cita, como consequência positiva, a necessidade de esta modalidade pedagógica ligar-se a uma das principais tendências da relação ensino-aprendizagem contemporânea, que prega a formação de alunos proativos, capazes de criar seu próprio perfil de aprendizado. Ou seja, discentes que desenvolvam habilidades para tornar-se agentes centrais de sua própria formação. Arieira observa ainda que "outra função da EAD é permitir que pessoas excluídas do modelo tradicional de educação possam ser incluídas e ter seus direitos de acesso à educação e à informação garantidos" (ARIEIRA, 2009, p. 322).

Assim, o presente estudo parte do pressuposto de que a EAD constitui-se em adequada alternativa de autodesenvolvimento, como um mecanismo propiciador da inclusão digital e, principalmente, como um meio adequado de democratização do Ensino Superior cuja qualidade pode ser avaliada.

Nessa perspectiva de inclusão digital e democratização do ensino superior, o governo brasileiro empreendeu o programa intitulado Universidade Aberta do Brasil (UAB) procurando promover o acesso ao ensino superior das pessoas que não teriam oportunidade de cursar uma graduação presencial. Sobre a natureza e os objetivos da UAB, Stella Segenreich (2009) afirma que, na realidade, a UAB não é uma nova instituição educacional, pois não tem sede ou endereço. O nome faz referência a uma rede nacional experimental voltada para a pesquisa e para a educação superior (compreendendo formação inicial e continuada), formada pelo conjunto de IES públicas em articulação e integração com o conjunto de polos municipais de apoio presencial (2009, p. $215-216)^{2}$.

O Sistema UAB foi oficialmente instituído pelo Decreto $\mathrm{n}^{\circ}$ 5.800, de 8 de junho de 2006, de autoria da Presidência da República - Casa Civil, para "o desenvolvimento da modalidade educação a distância, com a finalidade de expandir e interiorizar a oferta de cursos e programas de educação superior no País"3.

No âmbito da UNICENTRO, a educação a distância é regulamentada pelo seu Núcleo de Educação a Distância (NEAD), o qual foi criado a partir da Resolução n 86/05, do seu Conselho de Ensino, Pesquisa e Extensão (CEPE) e tem como principais finalidades:

I - auxiliar no processo de difusão do conhecimento científico para os diferentes segmentos sociais;

II - oportunizar o acesso ao saber acadêmico, visando à redução das desigualdades sociais;

III - possibilitar a qualificação profissional, favorecendo a melhoria da qualidade de vida a uma maior parcela da população ${ }^{4}$.

O objeto deste artigo é o curso de licenciatura em História ${ }^{5}$ oferecido na modalidade a distância pela Universidade Estadual do Centro-Oeste (UNICENTRO) em convênio com a UAB.

\footnotetext{
${ }^{2}$ Para mais informações a respeito da Universidade Aberta do Brasil, ver também Zuin (2006, p. 935-954).

${ }^{3}$ Disponível em: http://www.uab.mec.gov.br.

${ }^{4}$ Art. $2^{\circ}$ do Regulamento do Núcleo de Educação a Distância da Universidade Estadual do Centro-Oeste UNICENTRO. Anexo à Resolução 86/2005 - CEPE/UNICENTRO, p. 1.

${ }^{5}$ Atualmente, a UNICENTRO oferta também os seguintes cursos de graduação na modalidade EAD: Administração, Artes e Pedagogia.
} 
Tendo em vista os objetivos do NEAD, e a demanda por licenciados em História na macrorregião de abrangência da UNICENTRO, o Conselho do Departamento de História (DEHIS), vinculado ao Campus Universitário Santa Cruz, em Guarapuava, decidiu em reunião do dia 14 de abril de $2008^{6}$ pela realização de uma experiência com a EAD na forma de oferta do curso de Licenciatura Plena em História na modalidade a distância, oferecido com base nos moldes curriculares praticados no sistema presencial. Tal condicionante se ligou diretamente à necessidade de avaliação das novas tecnologias empregadas, a partir de então, na formação de profissionais do campo da História. No final dos quatro primeiros anos (dezembro/2012) e, consequentemente, com a formação da primeira turma do curso de graduação em História na modalidade EAD, nova deliberação do Conselho Departamental definirá a continuação ou o encerramento da oferta de novas turmas. Após os trâmites necessários, o curso foi criado pela Resolução n ${ }^{\circ} 31$ do Conselho Universitário Superior (COU) da UNICENTRO, de 9 de fevereiro de 2009, com oferta de 300 vagas distribuídas nos polos de $\mathrm{Bi}$ turuna, Goioerê, Laranjeiras do Sul, Palmital e Pinhão.

Em 2011, o curso se encontrava no terceiro ano de sua primeira oferta, registrando um índice de evasão discente que gira em torno de $40 \%$ dos matriculados ${ }^{7}$. De acordo com Elaine Maria dos Santos e José Dutra de Oliveira Neto (2009), a evasão de alunos em cursos de EAD não é um fenômeno restrito, posto que inúmeras pesquisas buscam entender e explicar as motivações que levam os discentes a desistir de seus cursos. Os autores elencam algumas das principais causas: a não adaptação ao modelo de ensino, uma vez que a EAD exige do aluno proatividade $e$ certo grau de independência em relação à tradicional figura do professor presencial; e a inabi- lidade no manejo das tecnologias que requerem o uso de computador e principalmente da internet. Isso acaba por criar barreiras ao aprendizado dos estudantes que não conseguem acompanhar as atividades propostas no ambiente virtual de aprendizagem (AVA). Os pesquisadores citados apontam também, como obstáculo enfrentado por alguns discentes de cursos em ambiente EAD, a ausência do sentimento de grupo e a consequente falta de identidade como turma em razão do reduzido número de encontros presenciais entre os alunos.

Sendo assim, algumas questões nortearam o desenvolvimento do presente artigo: qual o perfil dos alunos do curso de licenciatura em História na modalidade EAD da UNICENTRO/UAB? O que os levou a optar pela modalidade à distância de ensino? Quais são suas opiniões no que concerne às vantagens e desvantagens do curso que escolheram? E, finalmente, como avaliam o curso e o material didático oferecido? A partir dessas questões norteadoras, definiu-se como objetivo principal deste estudo produzir subsídios para a avaliação do curso de História da UAB/UNICENTRO.

\section{Descrição da pesquisa}

Para a realização deste estudo, um questionário ${ }^{8}$ estruturado foi submetido, de maneira presencial, aos acadêmicos matriculados no curso de licenciatura em História EAD. De acordo com Valdete Boni e Sílvia Jurema Quaresma (2005), o questionário estruturado, ou seja, aquele que conta com opções de resposta predefinidas, tem se apresentado, entre os pesquisadores especializados, como uma das mais recorrentes maneiras de obter informações seriadas a respeito de diferentes processos sociopedagógicos. Uma das vantagens desse processo de coletar dados consiste na possibilidade de ausência do pesquisador. Os questionários podem ser remetidos ao público-alvo por malas diretas físicas, eletrônicas ou ser aplicados por outras pessoas envolvidas com a comunidade

${ }^{6}$ Conforme Ata $n^{\circ} 682$ das reuniões do Departamento de História - DEHIS.

${ }^{7}$ Fonte: Divisão de Apoio Acadêmico (DIAP) da UNICENTRO, em fevereiro de 2011. 
analisada. Além disso, esse modelo de entrevista permite que sejam alcançadas respostas objetivas, indispensáveis às análises seriais que resultam em índices, estimativas, proporções populacionais, projeções, entre outros. Por fim, vale acrescentar que o questionário estruturado "garante também maior liberdade das respostas em razão do anonimato, evitando vieses potenciais do entrevistador. Geralmente através do questionário obtêm-se respostas rápidas e precisas" (BONI; QUARESMA, 2005, p. 74).

Os questionários foram disponibilizados para os 185 alunos matriculados. Entretanto, apenas $149(80,5 \%)$ o responderam ${ }^{9}$. Como o número de questionários efetivamente preenchidos representa a maior parte dos alunos participantes, considera-se que há dados adequados e suficientes para a avaliação pretendida. Os acadêmicos foram convidados a responder questões de acordo com os seguintes enfoques: perfil do acadêmico, opinião acerca da modalidade de ensino a distância, aspectos técnicos e, por fim, avaliação. Para melhor discussão e entendimento dos resultados obtidos com a aplicação dos questionários, o artigo será dividido em quatro partes.

$\mathrm{Na}$ primeira parte, vamos apresentar o perfil do estudante a partir das seguintes questões; faixa etária, sexo, localização da residência (zona urbana ou rural) e se possui ou não outra formação de Ensino Superior. Na segunda parte, analisaremos o local de acesso dos alunos aos equipamentos de informática e acesso à plataforma Moodle ${ }^{\circledR}, 0$ que consideramos aspecto técnico.

Em seguida, a terceira parte desta análise consiste em perceber as opiniões dos discentes a respeito da educação a distância, qual foi sua motivação ao escolher o curso e o que considera vantagens e desvantagens desse método de ensino. Por fim, como quarta e última parte, temos a avaliação. Os acadêmicos foram convidados a avaliar o curso no qual estão inseridos e o material didático oferecido, bem como a apresentar seu grau de satisfação com o trabalho dos tutores, da coordenação pedagógica e com a própria graduação - o curso de licenciatura em História.

\section{Perfil do acadêmico}

Para podermos traçar o perfil do acadêmico do curso de licenciatura em História na modalidade $\mathrm{EAD}$, as questões aplicadas foram direcionadas a aspectos referentes a idade e sexo do cursista $e$ local de residência, mas preocupamo-nos principalmente em verificar se esse curso trata de uma primeira formação de ensino superior ou de um complemento em sua formação inicial, em alguns casos. Para a melhor compreensão dos dados obtidos com as respostas, as informações coletadas foram sistematizadas e representadas em gráficos. Nas páginas que seguem, estabeleceremos uma apreciação preliminar dos dados obtidos.

No que diz respeito à idade dos respondentes, podemos verificar pela Figura 1 que o maior percentual encontrado está na faixa acima de 40 anos, correspondendo a $28,8 \%$ das respostas obtidas (43 alunos). Em seguida, temos os alunos pertencentes à faixa etária entre 25 e 30 anos (22,1\%, ou 33 alunos). Além disso, foi possível verificar pequena diferença entre os percentuais de alunos pertencentes às faixas entre 19 e 25 anos, 30 a 35 anos e 35 e 40 anos $(15,5 \%-23$ alunos; $16,8 \%$ - 25 alunos; e 16,1\% - 24 alunos, respectivamente). Dessa forma, podemos verificar como característica desse grupo de respondentes que a procura pelos cursos na modalidade de EAD se dá mais entre pessoas pertencentes a uma faixa etária um pouco mais elevada do que a idade mais comum dos estudantes universitários em geral (entre 19 e 25 anos).

\footnotetext{
${ }_{8}$ As questões elaboradas para este estudo tomaram como referencial modelar útil o trabalho de Arieira (2009, p. 313-340).

9 Os questionários foram apresentados nos cinco polos EAD/UNICENTRO no dia 07 maio de 2011, quando os respondentes estavam reunidos para uma avaliação presencial da disciplina História Contemporânea I mediante anuência unânime dos presentes.
} 


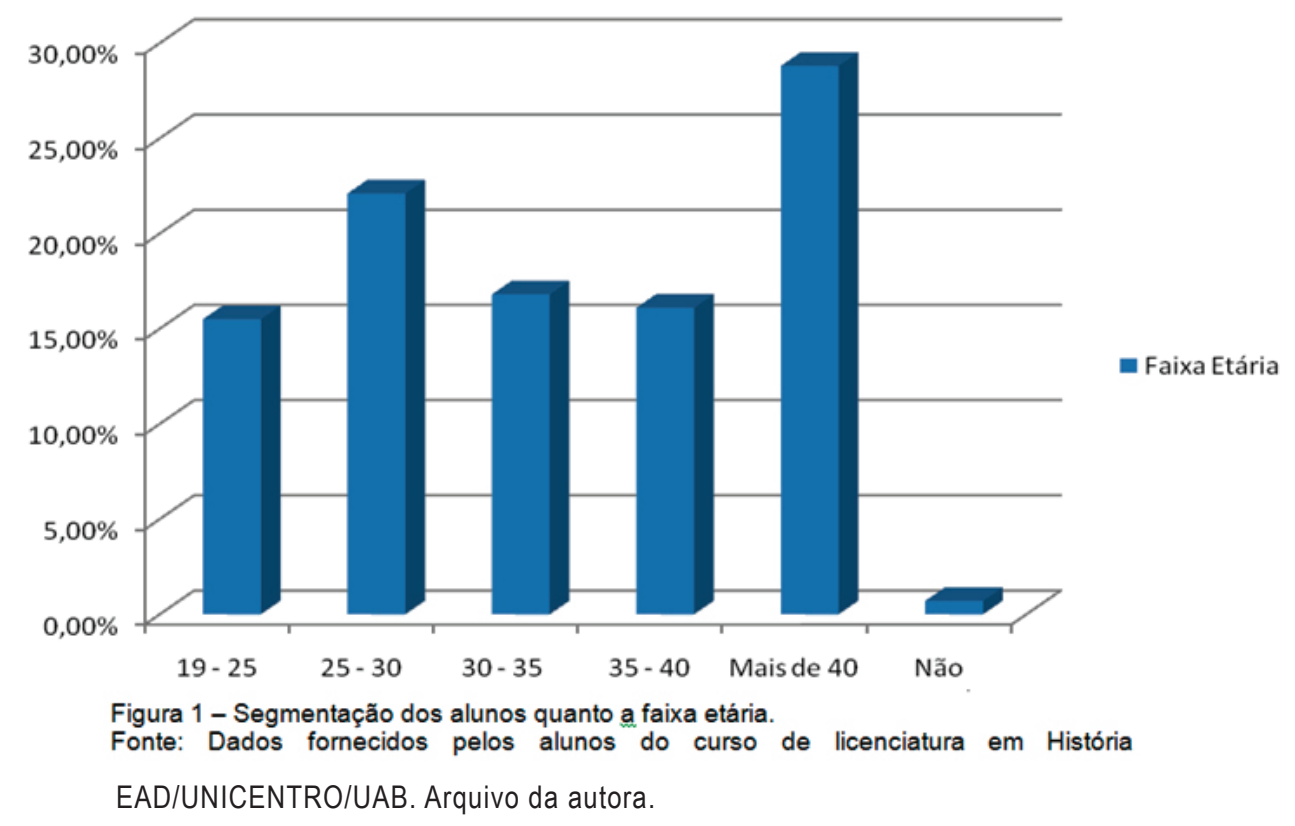

Quanto ao sexo dos acadêmicos do curso de licenciatura em História EAD da UNICENTRO, podemos verificar na Figura 2 a forte predominância feminina. As mulheres se mostraram como a grande maioria no curso, o que também pode ser verificado, por exemplo, nos cursos de licencia- tura no modelo presencial. Dos 149 alunos que responderam aos questionários, 107 (71,8\%) são mulheres, contra apenas $18,1 \%$ (o que corresponde a 27 alunos) de homens. Apenas 15 alunos $(10,1 \%)$ não responderam a essa questão.

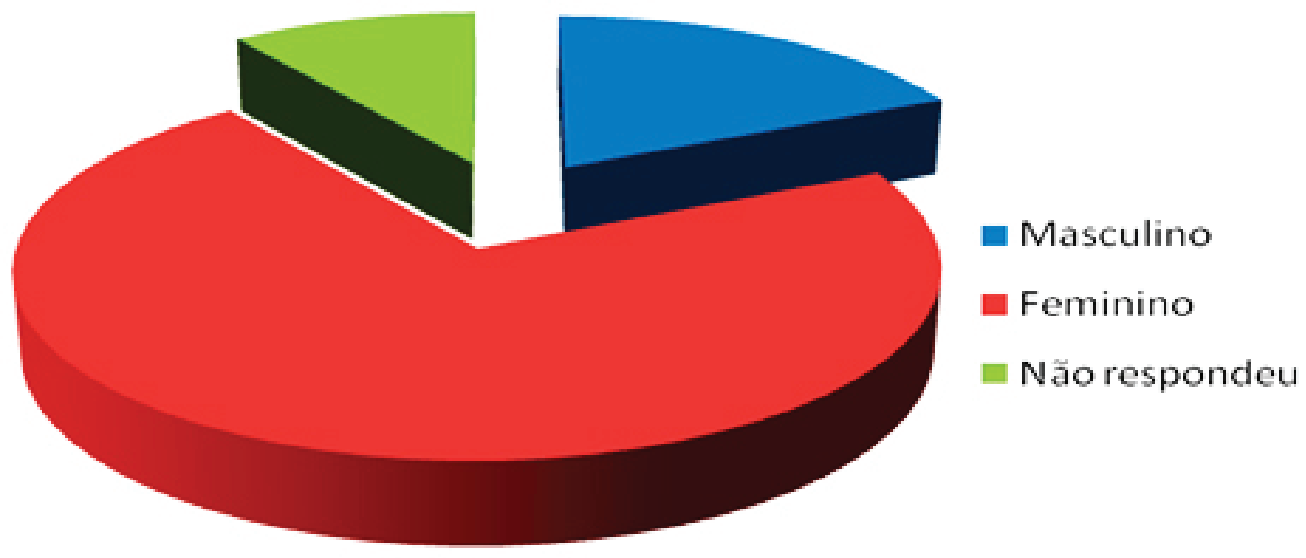

Figura 2 - Distribuiçăo dos alunos quanto a sexo. Fonte: Dados fornecidos pelos alunos do curso del licenciatura em História EAD/UNICENTRO/UAB. Arquivo da autora.

Outro fator importante para a nossa análise acerca do perfil do acadêmico do curso de História EAD consiste na área de residência desses estudantes. Pela Figura 3, podemos verificar que a maior parte dos respondentes afirmou residir em área urbana: $63,8 \%$, o que corresponde a 95 alunos, contra apenas $6,7 \%$ (10 alunos) pertencentes à zona rural. Os alunos que não responderam à questão somaram 29,5\% (44 alunos).

Apesar de as regiões próximas às sedes dos polos serem predominantemente rurais, podemos supor, por um lado, que a maior parte dos acadêmicos participantes da pesquisa reside nas cidades de localização dos polos de apoio presencial. 
Por outro lado, a proliferação de pequenas cidades e até mesmo bairros rurais e distritos (sem autonomia administrativa) pelo interior do Estado do Paraná certamente contribui para o reconhecimento, por parte dos alunos, de sua residência como localizada em zonas urbanas.

Entretanto, devemos lembrar que é necessário um estudo mais acurado das diferentes formas de urbanização evidenciadas na região abrangida pela pesquisa para aprofundamento da compreensão dos impactos da formação de profissionais de nível superior pela EAD na melhoria das condições de vida das pessoas residentes em zonas majoritariamente rurais.

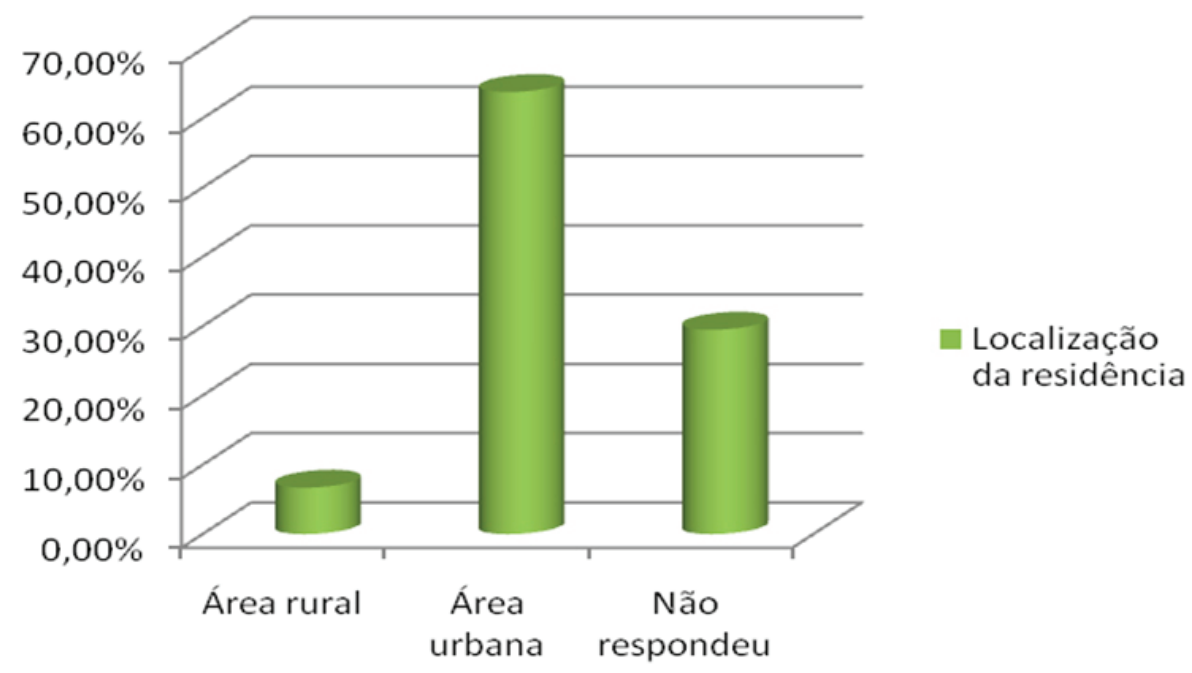

Figura 3 - Segmentação dos alunos conforme a localização da residência.

Fonte: Dados fornecidos pelos alunos do curso de licenciatura em História EAD/UNICENTRO/UAB. Arquivo da autora.

Além das informações já apresentadas, que podemos considerar de cunho pessoal, outro aspecto verificado diz respeito à formação acadêmica dos alunos; por ela, verificamos se esse aluno, hoje pertencente a um curso de graduação na modalidade a distância, já possuía outra formação em
Ensino Superior ou se este é o seu primeiro curso universitário. A Figura 4 demonstra a formação precedente ou primeira formação em Ensino Superior dos acadêmicos de História EAD; podemos verificar que a maioria dos alunos cursa sua primeira formação universitária: 62,4\% (93 alunos)

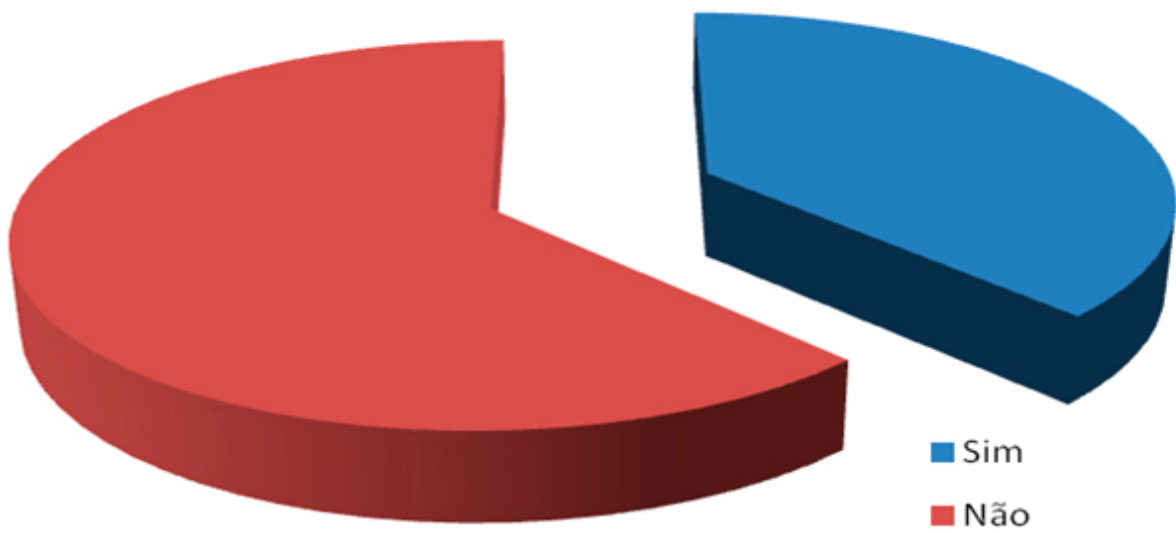

Figura 4 - Classificação conforme formação precedente no Ensino Superior. Fonte: Dados fornecidos pelos alunos do curso de licenciatura em História EAD/UNICENTRO/UAB. Arquivo da autora. 
não possuem formação em ensino superior anterior. Os outros $37,6 \%$ (56 discentes) optaram pela modalidade à distância para a realização de um segundo curso universitário - quer para aprimoramento da formação anterior na área pedagógica, quer por verem na EAD a oportunidade de adquirir outra atuação profissional.

\section{Aspectos técnicos}

Como aspecto técnico, consideramos essencialmente o local de acesso dos alunos à plataforma Moodle ${ }^{\circledR}$ e aos equipamentos de informática. Essa questão obteve 210 respostas, já que os alunos puderam indicar mais de uma alternativa, como mencionado anteriormente.
A Figura 5 demonstra o percentual das respostas obtidas. A grande maioria dos alunos acessa a plataforma Moodle em suas casas. Foram 113 respostas, que representam $53,8 \%$. O segundo lugar de acesso mais frequente dos alunos é no polo de apoio presencial, com 57 respostas contabilizadas, o que representa $27,1 \%$. O acesso a partir do local de trabalho dos estudantes configurou-se como terceiro local de acesso. Essa opção representou 15,7\% (33 respostas). Apenas 7 respondentes afirmaram que estudam em lan houses, o que representou apenas $3,4 \%$.
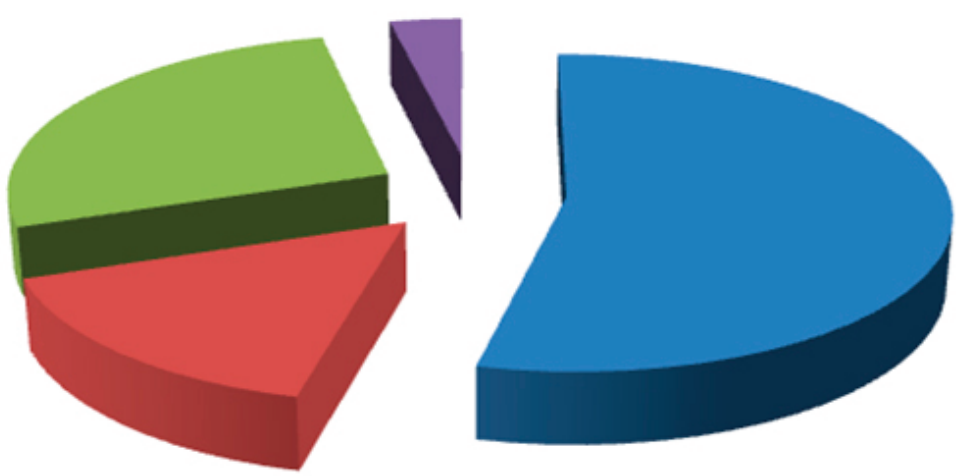

Casa

Trabalho

Polo de apoio

presencial

Lan House

Figura 5 - Classificação pelo local de acesso aos equipamentos de informática.

Fonte: Dados fornecidos pelos alunos do curso de licenciatura em História EAD/UNICENTRO/UAB. Arquivo da autora.

\section{Opinião do aluno}

Para a segunda parte do estudo, consideramos fundamental perceber qual foi motivação dos estudantes ao escolher um curso de graduação no modelo não presencial. Além disso, se faz indispensável verificar também a opinião do acadêmico com relação a essa modalidade de ensino, principalmente no que diz respeito às vantagens $e$ desvantagens da educação à distância.

Além de opções predefinidas, os alunos poderiam apontar outro fator além dos elencados nas alternativas das questões. Os dados sistematizados nas Figuras 6, 7 e 8 representam o número de respostas obtidas em cada questão, e não o número de alunos que participaram da pesquisa, uma vez que nessas perguntas os alunos poderiam marcar mais de uma alternativa.

Quanto à motivação, obtivemos 158 respostas. Dessas, podemos perceber, conforme a Figura 6, que o que motivou a maior parte dos alunos a cursar uma graduação na modalidade a distância foi a falta de tempo disponível para fazer um curso presencial. Esses alunos representam 42,4\% (67 respostas). A segunda resposta mais recorrente foi "Não há universidade em minha cidade", que representou 22,8\% (36 respostas). Em terceiro lugar aparece a obtenção de mais um título acadêmico, com 21,5\% (34 respostas). Somente um entrevistado assinalou a alternativa "Não sou disciplinado para cursar uma graduação presen- 
cial", representando $0,6 \%$ das respostas.

Como já citado, os alunos poderiam elencar outros fatores motivacionais para a escolha do curso em questão. Foram contabilizadas 20 respostas $(12,7 \%)$. Dentre os motivos mencionados podemos destacar principalmente o interesse pelo curso de História. Dessa maneira, a graduação a distância surgiu como uma oportunidade para os que se interessavam pelo curso, mas que, de outra forma, não poderiam cursá-lo.

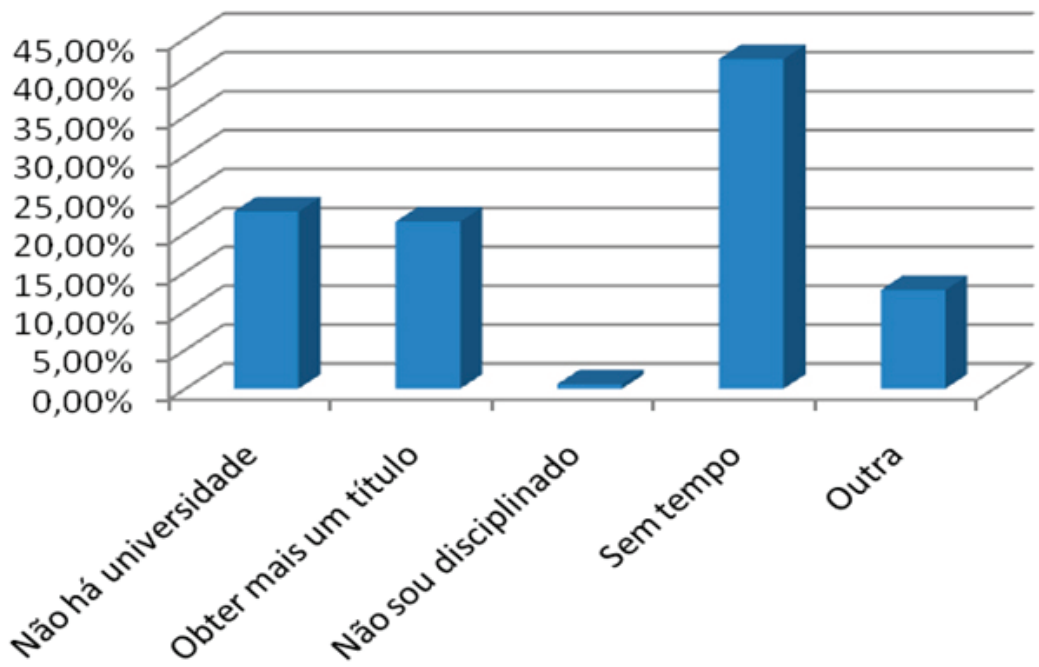

notivação

Figura 6 - Classificação segundo a motivação para realização do curso.

Fonte: Dados fornecidos pelos alunos do curso de licenciatura em História EAD/UNICENTRO/UAB. Arquivo da autora.

Os alunos expuseram também suas opiniões acerca das vantagens presentes em um curso de EAD. Foram obtidas 174 respostas, como podemos verificar na Figura 7. A principal vantagem apontada pelos estudantes foi que a EAD permite o acesso ao Ensino Superior de pessoas que não teriam condições de cursar uma graduação no modelo tradicional. Essa opção obteve 83 respostas, o que representa $47,7 \%$. A segunda vantagem mais apontada pelos alunos foi que o ensino a distância permite maior flexibilidade ao aluno. Não ser necessário estar em sala de aula todos os dias apresenta-se como um fator determinante, segundo a opinião discente. Essa opção obteve 72 respostas $(41,3 \%)$.

Poder estudar sozinho e recorrer ao professor ou tutor somente quando necessário obteve 17 respostas, o que representa 9,8\%. Apenas uma resposta considerou que o curso não tem nenhuma vantagem, assim como apenas uma resposta considerou a opção "outra vantagem não mencionada". Para esse aluno, o fato de fazer os próprios horários de estudo é a principal vantagem de um curso na modalidade a distância, o que poderíamos supor como aspecto positivo se considerarmos essa opinião como índice do desenvolvimento da autonomia dos alunos em relação ao sucesso nos próprios estudos.

Podemos considerar, portanto, que a graduação em História EAD da UNICENTRO está em conformidade com objetivo da UAB, que é permitir o acesso ao ensino superior das pessoas que não teriam oportunidade de cursar uma graduação presencial. 

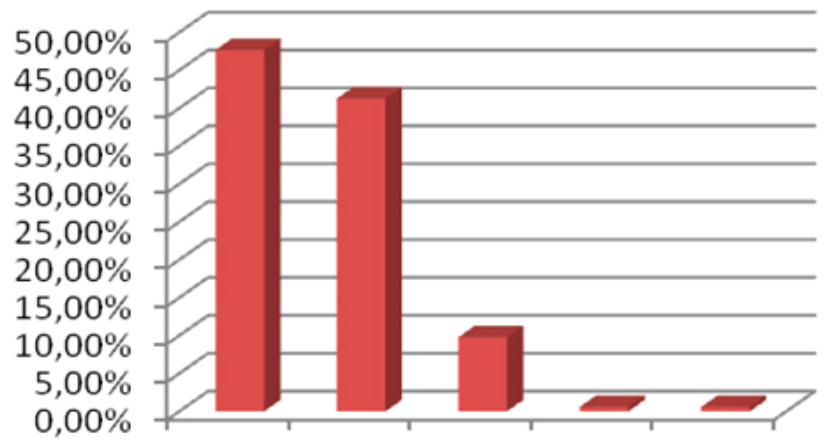

Vantagens do curso em EaD

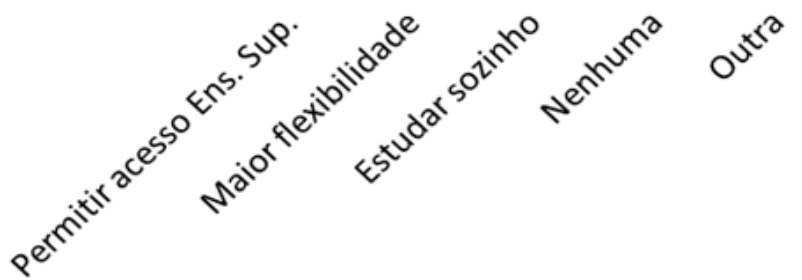

Figura 7 - Identificação das vantagens do curso na modalidade a distância.

Fonte: Dados fornecidos pelos alunos do curso de licenciatura em História EAD/UNICENTRO/UAB. Arquivo da autora.

Além das vantagens já mencionadas, os alunos puderam, da mesma forma, elencar as desvantagens encontradas por eles. A Figura 8 demonstra o percentual de respostas obtidas. Essa questão obteve 157 respostas; a maior parte delas considerou que não há nenhuma desvantagem no curso, o que representa $43,9 \%$ (69 respostas). Entre as desvantagens apontadas pelos demais, está o fato de não ter um professor presente constantemente, com 63 respostas (equivalente a 40,2\%). Em seguida, os alunos mencionaram a dificuldade de acesso à internet $e$ a dificuldade em trabalhar com tecnologia, as quais somaram, respectivamente,
$3,8 \%$ e $3,2 \%$ (6 e 5 respostas). Os alunos também mencionaram outras desvantagens além das já relacionadas; essas respostas somaram 8,9\% (14 respostas) e citam a falta de mais encontros presenciais, principalmente para apresentações de trabalhos, debates em turma, ou seja, a falta de mais atividades em classe, e o preconceito e a desvalorização existentes com os cursos de EAD. É possível verificar, a partir dessas respostas, a boa aceitação e o reconhecimento do curso pelos acadêmicos. Diante disso, constata-se que a EAD é um viabilizador para o ensino superior.

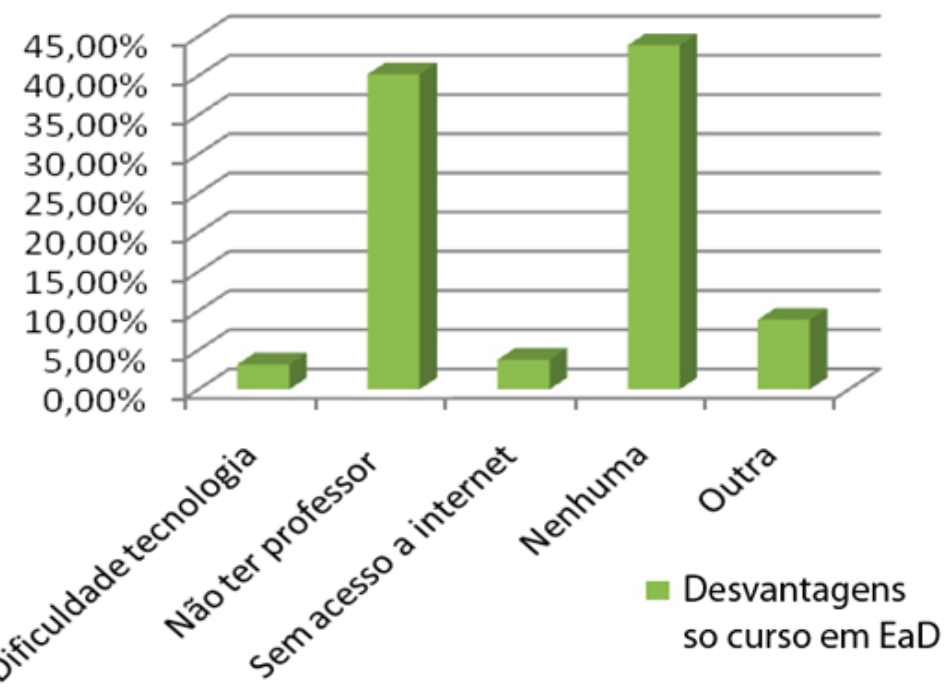

Figura 8 - Segmentação das desvantagens do curso na modalidade a distância. Fonte: Dados fornecidos pelos alunos do curso de licenciatura em História EAD/UNICENTRO/UAB. Arquivo da autora. 


\section{Avaliação}

Os alunos foram convidados a avaliar o material didático e o curso com base nas seguintes classificações: ótimo, bom, regular e péssimo. Como podemos verificar no Quadro 1, o material didático formulado pelos docentes do curso de licenciatura em História EAD e disponibilizado aos alunos foi avaliado de forma positiva, uma vez que foi considerado bom por $58,4 \%$ dos respondentes (87 alunos) e ótimo por $18,8 \%$ (28 alunos). Apenas $20,1 \%$ (30 alunos) o consideram regular, e somen- te $2,7 \%$ (4 alunos) o qualificam como péssimo.

Da mesma forma, o curso de licenciatura plena em História EAD foi avaliado positivamente. Podemos verificar no Quadro 1 que 86 alunos (o que representa $57,7 \%$ dos respondentes) consideram o curso ótimo; e 36,9\% (ou 55 estudantes) acham que o curso é bom; somente $5,4 \%$ (8 alunos) consideram o curso regular. Nenhum dos respondentes considerou o quesito "péssimo". Dessa forma, podemos perceber boa aceitação dessa modalidade de ensino por parte dos alunos.

\begin{tabular}{|l|c|c|c|c|}
\hline \multirow{2}{*}{ Questão } & \multicolumn{4}{|c|}{ Percentual de Respostas } \\
\cline { 2 - 5 } & Ótimo (\%) & Bom (\%) & Regular (\%) & Péssimo (\%) \\
\hline $\begin{array}{l}\text { Como avaliaria o } \\
\text { material didático } \\
\text { oferecido pelo } \\
\text { curso }\end{array}$ & 18,8 & 58,4 & 20,1 & 2,7 \\
\hline $\begin{array}{l}\text { Como avaliaria o } \\
\text { curso de } \\
\text { graduação em } \\
\text { História EaD }\end{array}$ & 57,7 & 36,9 & 5,4 & 0 \\
\hline
\end{tabular}

Quadro 1. Fonte: Dados fornecidos pelos alunos do curso de Licenciatura em História EaD/UNICENTRO/UAB. Arquivo da autora.

Além das avaliações apresentadas, os estudantes também registraram seus níveis de contentamento com o curso de graduação do qual fazem parte, com o trabalho dos tutores - tanto presenciais como a distância - e com a coordenação pedagógica do curso, usando as qualificações "muito satisfeito", "satisfeito", "pouco satisfeito" e "insatisfeito", conforme o Quadro 2.

Novamente podemos verificar que há boa aceitação a respeito de todos os itens por parte dos discentes, como demonstra o quadro $2: 67,8 \%$ dos alunos (o que corresponde a 101 alunos) dizem estar satisfeitos com o curso. 30 alunos $(20,1 \%)$ dizem estar muito satisfeitos, $11,4 \%$ (17 alunos) estão pouco satisfeitos e apenas $0,7 \%$ (1 aluno) se encontra insatisfeito com a graduação que está cursando.
A respeito do trabalho dos tutores presenciais $e$ dos tutores a distância, podemos perceber pouca variação nos percentuais das respostas obtidas. A grande maioria dos acadêmicos, composta de $68,5 \%$, ou, no caso, 102 alunos, se diz satisfeita com a tutoria.

A mesma média apresentada anteriormente, $20,1 \%$, correspondente a 30 alunos considera-se muito satisfeita com o trabalho desempenhado pelos tutores; $10,7 \%$ (16 alunos) estão pouco satisfeitos e apenas 1 aluno $(0,7 \%)$ está insatisfeito com os tutores.

Com relação aos níveis de satisfação com o trabalho desempenhado pela coordenação pedagógica do curso, notamos pequena variação nos resultados obtidos, conforme demonstra o quadro abaixo. 


\begin{tabular}{|l|c|c|c|c|}
\hline \multirow{2}{*}{ Questão } & \multicolumn{4}{|c|}{ Percentual de Respostas } \\
\cline { 2 - 5 } & $\begin{array}{c}\text { Muito } \\
\text { Satisfeito (\%) }\end{array}$ & Satisfeito (\%) & $\begin{array}{c}\text { Pouco } \\
\text { Satisfeito (\%) }\end{array}$ & $\begin{array}{c}\text { Insatisfeito } \\
(\%)\end{array}$ \\
\hline $\begin{array}{l}\text { Satisfação com o curso } \\
\text { de graduação em } \\
\text { História EaD }\end{array}$ & 20,1 & 67,8 & 11,4 & 0,7 \\
\hline $\begin{array}{l}\text { Satisfação com o } \\
\text { trabalho dos Tutores }\end{array}$ & 20,1 & 68,5 & 10,7 & 0,7 \\
\hline $\begin{array}{l}\text { Satisfação com a } \\
\text { Coordenação do Curso } \\
\text { de História EaD }\end{array}$ & 14,8 & 68,5 & 14,1 & 2,6 \\
\hline
\end{tabular}

Quadro 2. Fonte: Dados fornecidos pelos alunos do curso de Licenciatura em História EaD/UNICENTRO/UAB. Arquivo da autora.

Apesar de apresentar a mesma porcentagem de alunos satisfeitos com o trabalho da tutoria (68,5\%, que corresponde a 102 alunos), percebeu-se que uma porcentagem menor, que corresponde a 14,8\% (22 alunos) está muito satisfeita. Além disso, a média de alunos que consideram-se pouco satisfeitos apresentou um discreto aumento, uma vez que constatamos $14,1 \%$ das respostas (21 estudantes). Os insatisfeitos somaram apenas $2,6 \%$, o que corresponde a 4 alunos.

Com base nos dados apresentados é possível traçar o perfil - dentro das características propostas - dos acadêmicos do curso de licenciatura em História na modalidade a distância. Dessa forma, constatamos que o curso é formado em sua maioria por mulheres com mais de 40 anos, residentes em regiões urbanizadas e que têm esse como primeiro curso de formação universitária.

Constatou-se também quais as motivações deles ao escolherem um curso não presencial. A falta de tempo e de universidades em suas cidades $e$ a necessidade de obtenção de títulos, na mesma porcentagem da falta de universidades locais, foram considerados os principais motivos para aderência a essa modalidade de ensino.

Além das motivações, os alunos puderam demonstrar suas opiniões no que diz respeito às vantagens e desvantagens da EAD. A principal vantagem apresentada foi que a educação a dis- tancia permitiu o acesso ao ensino superior a pessoas que, de outro modo, não teriam oportunidade. Outro fator importante a ser considerado diz respeito à flexibilidade que a EAD proporciona ao discente, uma vez que esse aluno pode fazer seus próprios horários de estudo e seu perfil de aprendizagem. Ou seja, essa modalidade de ensino colabora para a formação de alunos proativos e autônomos.

Os alunos consideram que não há qualquer desvantagem na modalidade de ensino em questão, o que demonstra que os alunos estão se adaptando a essa modalidade e que consideram a graduação a distância como uma boa oportunidade de imersão no ensino superior. Contudo, não podemos deixar de destacar que cerca de metade dos respondentes afirma ser uma desvantagem o fato de "Não ter professor", demonstrando não identificar esse personagem na EAD.

As respostas indicaram que os discentes têm fácil acesso aos equipamentos de informática e ao ambiente virtual de aprendizagem, uma vez que a maioria deles faz uso dos equipamentos em suas próprias residências. Isso se torna um facilitador para a implementação e desenvolvimento dessa modalidade de ensino.

Por fim, pôde-se observar também como os alunos avaliam alguns aspectos pertinentes ao curso e puderam demonstrar seus níveis de satisfação 
com ele. As análises demonstraram que os acadêmicos avaliaram tanto o curso como o material didático oferecido de forma positiva, tendo em vista que a maior parte das respostas considerou esses aspectos como bons e ótimos.

Com relação aos níveis de satisfação, podemos verificar também que há uma boa aceitação por parte dos alunos, já que em todos os quesitos avaliados a maior parte dos estudantes considerou-se satisfeita.

Assim, há um indicativo, considerando as respostas desta amostra, de que a modalidade EAD deste curso cumpre seu objetivo principal, que é ser um eficaz instrumento para a universalização do acesso ao ensino superior e para a requalificação do professor em outras disciplinas, fortalecendo a escola no interior do Brasil, minimizando a concentração de oferta de cursos de graduação nos grandes centros urbanos e evitando o fluxo migratório para as grandes cidades .

Acreditamos, entretanto, que este primeiro esforço de avaliação do curso de licenciatura em História na modalidade a distância oferecido pelo Departamento de História do campus Santa Cruz da UNICENTRO pode contribuir para a busca de aperfeiçoamento da proposta inicial e servir como parâmetro para outras avaliações a serem realizadas no futuro. Além disso, as informações obtidas neste estudo podem subsidiar a coordenação do curso para alinhamento e/ou elaboração de estratégias para tomada de decisão. No mais, colocamos à disposição dos especialistas no tema um conjunto novo de dados e projeções quantitativas, os quais, uma vez cotejados com os obtidos em outras regiões e experiências de EAD no Brasil e no exterior, podem ser úteis ao aprimoramento dessa modalidade de ensino, que, a nosso ver, não tem mais o seu futuro colocado em dúvida.

\section{Referências bibliográficas}

ALMEIDA, Maria Elizabeth Bianconcini de. Educação a distância no Brasil: diretrizes políticas, fundamentos e práticas. Disponível em: http://cecemca.rc.unesp.br/cecemca/EAD/artigos/atigo\%20Beth\%20 Almeida\%20RIBIE.pdf. Acesso em 24 set. 2010.

ARIEIRA, Jaílson de Oliveira et al. Avaliação do aprendizado via educação a distância: a visão dos discentes. Ensaio: Avaliação e Políticas Públicas em Educação. Rio de Janeiro, v. 17, n. 63, p. 313-340, abr/jun. 2009.

BELLONI, Maria Luiza. Ensaio sobre a educação a distância no Brasil. Revista Educação e Sociedade, Campinas, ano XXIII, n. 78, p. 117-142, abr. 2002.

BONI, Valdete; QUARESMA, Sílvia Jurema. Aprendendo a entrevistar: como fazer entrevistas em Ciências Sociais. Em Tese Revista Eletrônica dos Pós-Graduandos em Sociologia Política da UFSC, v. 2 n. 1, p. 68-80, jan.-jul. 2005.

MORAN, José Manuel. Avaliação do Ensino Superior a Distância no Brasil. Disponível em: http://www. eca.usp.br/prof/moran/avaliacao.htm. Acesso em: 25 jan. 2012.

SANTOS, Elaine Maria dos; OLIVEIRA NETO, José Dutra de. Evasão na Educação a Distância: identificando causas e propondo estratégias de prevenção. Paidei@ Revista Científica de Educação a Distância. Santos, v. 2 n. 2, dez. 2009.

SEGENREICH, Stella Cecília Duarte. ProUni e UAB como estratégias de EAD na expansão do Ensino Superior. Revista Pro-Posições, Campinas, v. 20, n. 2, p. 205-222, maio/ago. 2009.

ZUIN, Antonio A. S. Educação a distância ou Educação distante? O programa Universidade Aberta do Brasil, o tutor e o professor virtual. Revista Educação e Sociedade, Campinas, v. 27, n.96 - Especial, p. 935-954, out. 2006.

${ }^{11}$ Disponível em: http://www.uab.mec.gov.br. 